\title{
Food safety is truly everyone's business
}

\author{
Markus Lipp ${ }^{1}$
}

Published online: 14 May 2021

(c) Bundesamt für Verbraucherschutz und Lebensmittelsicherheit (BVL) 2021
In 2018, the 73rd Session of the General Assembly of the United Nations (UN) established that the World Food Safety Day would occur every year on 7 June (UN resolution $73 / 250^{1}$ ), in particular to help raise awareness that "there is no food security without food safety, and that in a world where the food supply chain has become more complex, "any adverse food safety incident may have global negative effects on public health, trade and the economy" and "that improving food safety contributes positively to trade, employment and poverty alleviation". The Food and Agriculture Organization (FAO) and the World Health Organization (WHO), two specialized agencies of the UN, alternate taking the leadership role in facilitating the celebration of World Food Safety Day, and for 2021, FAO has the lead.

\section{Food is more than science can tell}

This year's motto of World Food Safety Day is "Food Safety is Everyone's Business", which spurred some thoughts that I wanted to share. In my work, I lead a team of highly professional colleagues as well as regular meetings of scientific experts from around the world. We delve into the minutia of food safety-discussing the maximum levels and acceptable daily intake quantities of different substances. But food is so much more than science can tell, in fact, it is unlike any other consumer product. Food holds a proud part in all cultures and many of our memories are connected to food-making special dishes with family and friends and relishing a delicious meal. Forever imprinted in our minds is how much we enjoyed those meals as well as the people we shared them with and the occasion we celebrated. As food safety experts, the readers of this journal are experts to consider and evaluate dispassionately hazards and risks connected to

Markus Lipp

Markus.Lipp@fao.org

1 Food and Agriculture Organization (FAO) of the United Nations, Via delle Terme di Caracalla, 00154 Roma, Italy food, routinely making judgements about recalls, acceptable daily limits and for what chemical or microbial target to test, in order to determine whether a food is safe for human consumption. There is one caveat though, most consumers are not food safety experts. Let's not forget that for most consumers, food safety is fundamentally different than the safety of any other consumer product, and people's reaction to food safety risks is fundamentally different than for any other product they purchase.

Food is intimate; it becomes part of us. Food is passion; we have strong likes and dislikes when it comes to food. Food is also a way to communicate. The topic of food fills many hours with passionate and engaged discussions, and almost every language has a saying for food being the means to gain the affection of another person. Most of us express ourselves through food choices we make. We choose the food to celebrate a special occasion very carefully. We take extra care and pride in providing our children with good, healthy and, above all, safe food. And many find great satisfaction in seeing others enjoy the food they prepared. One could even say food is love. So intimately woven in the fabric of our lives, food is unique, nothing compares to it.

\section{Safety is the implicit definition of food}

The consequence is that food safety is a special topic, a topic that deeply affects every single person. This is where events like the World Food Safety Day can help raise awareness of understanding with everyone. Food safety is truly everyone's business-farmers, food workers, retailers and consumers. Everyone in the food system needs to work together not only to keep our food safe, but also our food systems operating. Above all, what separates food from a simple agricultural product is the dependability that it is safe to eat. In fact safety is an implicit definition of food. If it is unsafe, we reject or discard it, it has right then and there transformed from food to garbage or waste. If it is not safe, it is not food...it is just

\footnotetext{
1 https://www.un.org/en/ga/search/view_doc.asp?symbol=A/RES/73/ 250 Accessed 20 April 2021.
} 
as simple as that. The current pandemic has highlighted that more than ever, and, at the same time, made us aware that we need to support their transformation. What unites us is not only the fact that every person needs food every day — but the fact that our food supply, our food system, is truly global.

Food business operators and regulatory agencies have succeeded in minimizing disruptions to our food supply in an amazingly effective manner. However, it has not been perfect response-it was not an equitable response. Not all people on our planet have been equally protected against food shortages. Many are left behind, especially in low and middle-income countries. Due to the disruptions caused by the current pandemic, food insecurity ${ }^{2}$ and hunger has increased globally, and it is expected to increase even further. This is not acceptable, and we must not leave anyone behind. Our global agri-food systems can only be as strong as their weakest part. To strengthen our agri-food systems, we have to strengthen the parts that are the weakest-and to achieve that, we have to work closer together. The only way to effectively address a global threat is through the efficient global collaboration of all stakeholders of our food systems. We must strengthen our global coordination and response capabilities from both the public and private sector. While the challenges are many, I would like to highlight again the importance of food safety. Ensuring that our food is safely produced, processed, distributed and consumed throughout the entire supply chain, form farm to fork, from field to chopstick, from boat to bowl concerns us all.

In the decade of action towards achieving the UN Sustainable Development Goals, ${ }^{3}$ we can step up efforts on food safety, which is part of that agenda. This year's World Food Safety Day brings it into the spotlight, to help prevent, detect and manage foodborne risks. Safe food contributes to economic prosperity, boosting agriculture, market access, tourism and sustainable development. Food safety supports many SDGs, which cannot be achieved as long as food is not safe for everyone. In particular, food safety is a critical enabler for:
- Zero Hunger (Goal 2): There is no food security without food safety. Ending hunger is about all people having access to safe, nutritious and sufficient food all year round.

- Good Health and Well-Being (Goal 3): Food safety has a direct impact on people's health and nutritional intake. Foodborne diseases are preventable.

- Responsible Consumption and Production (Goal 12): When countries strengthen their regulatory, scientific and technological capacities to ensure that food is safe and of the expected quality throughout the food chain, they move towards more sustainable patterns of food production and consumption.

- Partnerships to achieve the Goals (Goal 17): A globalized world with annual food exports currently in excess of USD 1.6 trillion and complex food systems demands international cooperation across sectors to ensure food is safe. Food safety is a shared responsibility among governments, food industries, producers and consumers.

So as I go about my business, I'll continue to think about how food safety connects us all, how it depends on all of us playing our part.

Disclaimer The views expressed in this publication are those of the author and do not necessarily reflect the views and policies of the Food and Agriculture Organization of the United Nations.

Publisher's Note Springer Nature remains neutral with regard to jurisdictional claims in published maps and institutional affiliations.

\footnotetext{
2 "A situation that exists when people lack secure access to sufficient amounts of safe and nutritious food for normal growth and development and an active and healthy life." http://www.fao.org/fileadmin/ templates/ERP/uni/FIMI.pdf Accessed 20 April 2021.

3 https://www.un.org/sustainabledevelopment/sustainable-devel opment-goals/ Accessed 20 April 2021.
} 